Journal of Applied Fluid Mechanics, Vol. 1, No. 1, pp. 62-70, 2008. Available online at www.jafmonline.net, ISSN 1735-3645.

DOI: $10.36884 / \mathrm{jafm} .1 .01 .11838$

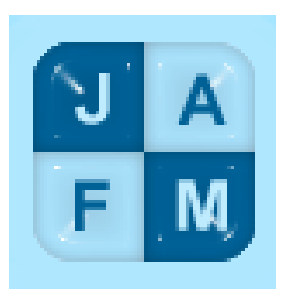

\title{
Numerical Modelling of Tracer Transport in Unsaturated Porous Media
}

\author{
T. Bunsri ${ }^{1}$ M. Sivakumar ${ }^{2}$ and D. Hagare ${ }^{3}$ \\ ${ }^{1}$ National Centre of Excellence for Environmental and Hazardous Waste and Management, Department of Environmental \\ Engineering, Faculty of Engineering, King Mongkut's University of Technology Thonburi, Bangkok 10140, Thailand \\ ${ }^{2}$ Sustainable Water and Energy Research Group (SWERG), School of Civil, Mining and Environmental Engineering, \\ Faculty of Engineering, University of Wollongong, NSW 2522, Australia \\ ${ }^{3}$ Sterling College, Level 3, 770 George Street, Sydney, NSW 2000, Australia \\ Email: thidarat.bun@kmutt.ac.th
}

(Received January 22, 2007; accepted May 26, 2007)

\begin{abstract}
Many types of chemical substances have been used as tracers to estimate the migration of contaminant in a porous media. Inorganic ionic compounds have been applied extensively as hydrogeologic tracers. Sodium chloride is generally used as a tracer since this common salt does not degrade or get removed from the system. Movement of tracer could be described as migration of a non-reactive constituent. A tracer transport numerical model was developed according to the advectivedispersive contaminant transport equation in unsaturated porous media. The governing equation was solved numerically and coded in MATLAB program. The objectives of this study were to develop a model for estimating the non-reactive constituent transport in the unsaturated porous media and to determine the impact of ionic strength of tracer and the effect of the thickness of porous media. The experiments were conducted with two different sodium chloride tracer concentrations (low strength-200 mg/L and high strength-500 mg/L) and for two different soil depths $(5$ and $20 \mathrm{~cm}$ ). The observation and simulation data indicate that the interference from soil background concentration is significant, provided that the high strength tracer is applied. As expected, the tracer transport in the thick layer took longer elapse time than in the thin layer. The simulation results using the developed model corresponded very well with the observed data.
\end{abstract}

Keywords: Advective-Dispersive Transport, Numerical Model, Tracer Test, Unsaturated Soil.

\section{NOMENCLATURE}

C tracer concentration; $\mathrm{g} \mathrm{cm}^{-3}$

$D_{M} \quad$ molecular diffusion coefficient; $\mathrm{cm}^{2} \mathrm{~h}^{-1}$

$D_{z} \quad$ dispersion coefficient; $\mathrm{cm}^{2} \mathrm{~h}^{-1}$

$k_{r w} \quad$ relative conductivity; $\left(0 \leq k_{r w} \leq 1\right)$; unitless

$K_{z Z} \quad$ saturated hydraulic conductivity; $\mathrm{cm} \mathrm{h}^{-1}$

$K_{z z} k_{r w}$ relative hydraulic conductivity; $\mathrm{cm} \mathrm{h}^{-1}$

$m \quad$ hydraulic properties coefficient; unitless

$M \quad$ specific moisture capacity; $\mathrm{cm}^{-1}$

$n \quad$ hydraulic properties coefficient; unitless

$N_{i} \quad$ stiffness functions; unitless

$N_{j} \quad$ shape functions; unitless p hydraulic properties coefficient; $\mathrm{cm}^{-1}$

$q_{z} \quad$ Darcy's velocity; $\mathrm{cm} \mathrm{h}^{-1}$

$t \quad$ previous time step; unitless

$t+\Delta t$ current time steps; unitless

$\mathrm{z} \quad$ vertical direction (positive upwards); $\mathrm{cm}$

$\theta$ volumetric water content; $\mathrm{cm}^{3} \mathrm{~cm}^{-3}$

$\theta_{r} \quad$ residual soil moisture contents; $\mathrm{cm}^{3} \mathrm{~cm}^{-3}$

$\theta_{s} \quad$ saturated moisture contents; $\mathrm{cm}^{3} \mathrm{~cm}^{-3}$

$\lambda$ dispersivity; $\mathrm{cm}$

$v \quad$ pore water velocity $;\left(=q_{z} / \theta\right) ; \mathrm{cm} \mathrm{h}^{-1}$

$\psi$ pressure head; $\mathrm{cm}$ 


\section{INTRODUCTION}

The tracers are useful for characterizing unsaturated water movement in the porous media. Many substances could be applied as tracers into unsaturated porous media. The tracers used could be classified into six categories including ions, dyes, gases, isotopes, water temperature and particulates. The ionic tracers are less toxic than others, and thus they are applied extensively. The ionic tracers include common salts, such as $\mathrm{Cl}^{-}, \mathrm{NO}_{3}^{-}, \mathrm{Br}^{-}, \mathrm{Ca}^{2+}, \mathrm{K}^{+}$etc. Most of these ionic tracers are anions, which are less affected by the porous media (Gelhar et al. 1992; Boulding and Ginn 2004). The retardation of anion due to absorption and precipitation increases, if the $\mathrm{pH}$ of the system decreases. The cation tracer could react to the clay minerals, especially $\mathrm{Na}^{+}$and $\mathrm{Ca}^{2+}$, through the ion exchange process (Mattson 1929). The ionic tracers are non-compost materials, and tracer loss is negligible. However, soil sometimes contains large quantities of ions, especially $\mathrm{Cl}^{-}$and $\mathrm{NO}_{3}{ }^{-}$, hence high tracer concentration is required for these high background concentration sites. If the large amounts of tracers are applied, they could potentially affect adversely on water quality similar to the pollutants (Grisak and Picken 1980a, b; Everts et al. 1989). The applications of $\mathrm{NaCl}$ tracer have been used by many researchers (Mather et al. 1969; Warrick et al. 1971; Grisak and Picken 1980a, b; James and Rubin 1986; Nützmann et al. 2002; Sato et al. 2003) to determine the characteristics of the water flow and the solute transport in unsaturated soils.

A number of models have been developed in the literatures for the prediction of the conservative tracer transport. These models are based on the advective-dispersive solute transport equation. This governing equation can be solved by two different techniques namely the analytical solution and the numerical approach. Most of the referenced models (Warrick et al. 1971; James and Rubin 1986; Wallach and Steenhuis 1998; Nützmann et al. 2002; Sato et al. 2003; Toride et al. 2003) relied on the analytical solution, which contained many boundary limitations. Some numerical tracer transport models have also been proposed (Grisak and Picken 1980a, b; Picken and Grisak 1981); however, they cannot apply to the unsaturated soil condition. The practical applications of the developed model in this paper are to estimate the tracer travel time and to evaluate the appropriate conditions for tracer applications.

\section{GOVERNING EQUATIONS FOR TRACER TRANSPORT MODEL}

One-dimensional tracer transport in unsaturated soil in vertical $\mathrm{z}$ direction is given using the advection dispersion equation as (Fetter 1992; Schnoor 1996):

$\frac{\partial C}{\partial t}=D_{z} \frac{\partial^{2} C}{\partial z^{2}}-q_{z} \frac{\partial C}{\partial z}$

The dispersion coefficient couples both mechanical and molecular diffusion, and the equation was given as (Fetter 1992; van Genuchten and Wierenga 1986):

$$
D_{z}=\lambda v+D_{M}
$$

Richards' equation is applied to determine Darcy's velocity, which was presented in Eq. (1). Richards' equation was given as (Ségol 1993):

$$
M \frac{\partial \psi}{\partial t}=\frac{\partial}{\partial z}\left(K_{z z} k_{r w}\left(\frac{\partial \psi}{\partial z}+1\right)\right)
$$

Richards' equation contained non-linear hydraulic parameters: $M$ and $K_{z z} k_{r w}$, which could be evaluated using van Genuchten (1980) model. The relevant equations are given as follows.

$$
\begin{aligned}
& \theta=\theta_{r}+\frac{\theta_{S}-\theta_{r}}{\left(1+(p|\psi|)^{n}\right)^{m}} \\
& K_{\mathrm{zz}} k_{r w}=K_{\mathrm{zZ}} \frac{\left[1-(p|\psi|)^{n-1}\left[1+(p|\psi|)^{n}\right]^{-m}\right]^{2}}{\left[1+(p|\psi|)^{n}\right]^{m / 2}}
\end{aligned}
$$

\section{NUMERICAL SOLUTIONS FOR TRACER TRANSPORT MODEL}

The advective-dispersive solute transport (Eq. (1)) and Richards' (Eq. (3)) equations are solved by the Galerkin technique. The numerical solution is arranged in systematically algebraic matrices using the finite element method (FEM) (Segerlind 1984; Ségol 1993). The numerical solution and the algebraic matrix system are given as follows.

Tracer transport model:

$$
\left\{\left[P_{i j}\right]+\left[Q_{i j}\right]\right\} C_{j}+\left[Q_{i j}\right] \frac{\partial C_{j}}{\partial t}=\left\{S_{i}\right\}
$$

where

$$
\begin{aligned}
& {\left[P_{i j}\right]=\sum_{e} \int_{z=0}^{z=L}\left(D_{z} \frac{\partial N_{i}}{\partial z} \frac{\partial N_{j}}{\partial z}+N_{i} \frac{\partial N_{j}}{\partial z} q_{z}\right) d z} \\
& {\left[Q_{i j}\right]=\sum_{e} \int_{z=0}^{z=L} N_{i} N_{j} \theta d z} \\
& \left\{S_{i}\right\}=\left.N_{i} D_{z}\left(\frac{\partial C}{\partial z}\right)\right|_{z=0} ^{z=L}
\end{aligned}
$$

Richards' equation:

$$
\left[A_{i j}\right] \psi_{j}+\left[B_{i j}\right] \frac{\partial \psi_{j}}{\partial t}=\left\{E_{i}\right\}
$$

where 


$$
\begin{aligned}
& {\left[A_{i j}\right]=\sum_{e} \int_{z=0}^{z=L} K_{z z} k_{r w}\left(\frac{\partial N_{i}}{\partial z} \frac{\partial N_{j}}{\partial z}\right) d z} \\
& {\left[B_{i j}\right]=\sum_{e} \int_{z=0}^{z=L} N_{i} N_{j} M d z} \\
& \left\{E_{i}\right\}=\left.N_{i} K_{z z} k_{r w}\left(\frac{\partial \psi}{\partial z}+1\right)\right|_{z=0} ^{z=L}-\sum_{e} \int_{z=0}^{z=L} K_{z z} k_{r w} \frac{\partial N_{i}}{\partial z} d z
\end{aligned}
$$

The algebraic matrix system is formed with linear Lagrange function. The iteration process is investigated by the single Picard iteration as follows (Ségol 1993).

Tracer transport model:

$$
\begin{aligned}
& \left\{\left(\frac{1}{2}\left(\left[P_{i j}\right]+\left[Q_{i j}\right]\right)\right)+\frac{1}{\Delta t}\left[Q_{i j}\right]\right\}\left(\{C\}^{t+\Delta t}-\{C\}^{t}\right) \\
& =\left\{S_{i}\right\}-\left(\left[P_{i j}\right]+\left[Q_{i j}\right]\right)\{C\}^{t t}
\end{aligned}
$$

Richards'equation:

$$
\left(\frac{1}{2}\left[A_{i j}\right]^{t}+\frac{1}{\Delta t}\left[B_{i j}\right]^{t}\right)\left(\{\psi\}^{t+\Delta t}-\{\psi\}^{t}\right)=\left\{E_{i}\right\}-\left[A_{i j}\right]^{t}\{\psi\}^{t}
$$

\section{MATERIALS AND METHODS}

The laboratory scale soil column set up is illustrated in Figure 1. The infiltration column was fabricated from a plexi-glass tube of $6.59 \mathrm{~cm}$ inside diameter, and the total length was $30 \mathrm{~cm}$. All soil column tests were packed with the disturbed topsoil sample and the bulk density was controlled at $1.25 \mathrm{~g} / \mathrm{cm}^{3}$.

The soil hydraulic properties test was undertaken using the dynamic method (Klute 1986). The pore pressure head at particular elevations were measured using tensiometers. The water content was analysed using a gravimetric method (Rayment and Higginson 1992). Three series of tracer tests were conducted that included: 1) low strength tracer with thin soil layer, 2) high strength tracer with thin soil layer and 3) high strength tracer with thick soil layer. The sodium chloride concentration was determined using the Electrical Conductivity (EC) 1:5 soil water extraction method (Rayment and Higginson 1992). The details of soil column tests are provided in Table 1.

\section{RESULTS AND DISCUSSIONS}

The soil characteristics are evaluated and the summary is given in Table 2. Soil contains some minerals that may interfere with the EC measurement. This background EC concentration was found to be equivalent to $117 \mathrm{mg} / \mathrm{L}$ sodium chloride solution. Hence higher concentration of 200 and $500 \mathrm{mg} / \mathrm{L} \mathrm{NaCl}$ tracer solution were chosen and their equivalent $\mathrm{EC}$ values are 0.130 and $0.503 \mathrm{mohs} / \mathrm{cm}$, respectively.

\subsection{Soil hydraulic properties}

The water retention curves are illustrated in Figure 2. $\theta_{S}$ and $\theta_{r}$ are found to be 0.42 and 0.04 , respectively. The coefficients: $m, n$ and $p$ were evaluated as 0.4026 , 1.6740 and $0.0249 \mathrm{~cm}^{-1}$, respectively.

\subsection{Unsaturated water movement}

The input parameters for Richards' equation are presented in Table 3.

The pressure head profiles for the thin soil layer are shown in Figure 3. The simulation results indicate that about half of soil column reached the full saturation condition within 8 hours. This implies that the whole column may reach the full saturation condition within 16 hours based on simulation. This statement was remarkably close with the observation. During the experiments, the first drop of filtrated water was percolated out after 18 hours of continuous feeding. These pressure head boundary conditions provide excellent support to the time-varying infiltration flow rate.

The simulated pressure head profiles for the thick soil layer are shown in Figure 4. By estimation, the travel time of feeding water in the thick soil layer should be 64 hours. The first drop of filtrated sample was observed after applying the tap water for 66 hours. Water moved through the thin and thick soil layer within 16-18 and 64-66 hours, respectively. The movement of water through the thin soil layer was four times faster than in the thick soil layer. Coincidently, the thickness of thin layer was four times less than the thick layer. Therefore, there was no retardation effect of migration of water through both soil thicknesses.

\subsection{Tracer transport in unsaturated soil}

The input parameters used for the tracer transport model are summarised in Table 4. The tracer concentration profiles for $\mathrm{T}-1$ are presented in Figure 5. The estimation of tracer retention time in the thin soil layer was 16 hours. Regarding the observed data, the maximum tracer concentration was $176 \mathrm{mg} / \mathrm{L}$, which was less than the feed concentration of $200 \mathrm{mg} / \mathrm{L}$. This loss might be a result of the ion exchange process onto soil minerals (Mattson 1929).

The tracer transport under the advection-dispersion mechanisms, will consume longer retention time than the water. The averaged $D_{z}$ values for each time intervals are given in Table 5. The calculated coefficient of 0.01-0.2 $\mathrm{cm}^{2} / \mathrm{h}$, lines within the acceptable range. The estimated effective diffusion coefficient of $\mathrm{NaCl}$ tracer is 0.037 $\mathrm{cm}^{2} / \mathrm{h}$ (Picken and Grisak 1981). The $\mathrm{D}_{z}$ is affected by time varying parameters, which depends on the hydrodynamics dispersion. Darcy's and pore velocities are the key parameters, which vary with time and the hydrodynamics dispersion is non-linear (Boulding and Ginn 2004). 
The concentration profiles for T-2 are shown in Figure 6. These results indicate that tracer might travel through $70 \%$ of the height of the column depth within 11 hours. However, the estimated travel time of the tracer is 16 hours which is closer to the retention time of water. Moreover, the maximum tracer concentrations were observed in the range of $494-497 \mathrm{mg} / \mathrm{L}$.

The migration of tracer through these thin unsaturated soil layers could be clearly observed, when the high strength tracer was applied. The estimated $\mathrm{D}_{z}$ values of these different tracer concentrations are not significantly different. Thus, the advection was the main mechanism, which controls the tracer transport. Obviously, the marked difference between simulation and observation data in Figures 5 and 6 may be primarily due to the use of a single tensiometer to obtain the pressure head measurement. The estimated Darcy's velocities of the tests T- 1 and T- 2 contain some truncation error due to the measurement of pressure gradient. Therefore, the advection-dispersion tracer transport parameters may be underestimated. Better match between simulation and experimental observations is obtained when 5 tensiometers are used for T-3 as shown in Figure 7.

The travel time of tracer in the thick soil layer is approximately 80 hours. The estimated tracer travel time was 14 hours longer than the water travel time. This indicates that the thickness of soil layer might potentially affect the tracer transport. Besides, the maximum concentration of tracer was found to be in the range of 488$497 \mathrm{mg} / \mathrm{L}$. These maximum tracer concentrations were not different what was found in T-2. This indicates that the losses of tracer concentration could be negligible. The dispersion coefficient for this experiment is given in Table 6.

The $\mathrm{D}_{\mathrm{z}}$ values for the thick soil layer are higher than the thin soil layer. This fact suggests that the large scale spreading of tracer may occur and this may be the reason for the difference in elapsed travel time. By statistical comparison, the developed model could precisely predict the pressure head and tracer concentration profiles, especially for the case T-3. This claim relies on the number of tensiometers used as increase a number of tensiometers could precisely identify the boundary conditions and hence accurately measure Darcy's and pore velocities. Thus, the advectiondispersion parameters involved the model could be estimated precisely.

The ionic tracer might be applied to the soil sample contains large quantities of ion; however, the applied tracer concentration must be significantly higher than the background concentration. The advection-dispersion parameters could be estimated accurately, if the pressure head boundaries are measured precisely. A long elapsed travel time in the thick soil layer is observed because of a large scale spreading of tracer.

\section{CONCLUSION}

It was shown that a tracer test could be used to evaluate the retention and movement of water in unsaturated soil conditions. The advective-dispersive solute transport was the main governing equation for the developed model. The model was solved numerically using the Galerkin finite element technique. Unsaturated infiltration flow velocity was estimated using Richards' equation. From the results, it is clear that the developed tracer transport model could generate accurate simulations results for all tracer transport conditions and also effectively estimates the diffusion-dispersion coefficients. The high strength tracer concentration and the thin soil layer could be the best solution for the estimation of unsaturated water movement in this topsoil sample. The high strength tracer concentration could overcome the interference of background concentration contained in the soil sample. In the thick soil layer, the tracer travel time could be extended by the diffusion mechanism and the high dispersion could potentially cause large spreading of the tracer.

\section{ACKNOWLEDGEMENTS}

Funding support for this research was provided by the National Research Centre for Environmental and Hazardous Waste Management (NRC-EHWM), and King Mongkut's University of Technology Thonburi, Bangkok, Thailand through PhD. scholarship to the first author to undertake the research at the University of Wollongong, Australia.

\section{REFERENCES}

Boulding, J.R. and J.S. Ginn (2004). Practical handbook of soil, vadose zone and ground water contamination $2^{\text {nd }} e d$. Florida, USA.: CRC Press LLC.

Everts, C.J., R.S. Kanwar, E.C. Alexander Jr. and S.C. Alexander (1989). Comparison of tracer mobilities under laboratory and field conditions. Journal of Environmental Quality 18, 491-498.

Fetter, C.W. (1992). Contaminant hydrology. New York, USA.: Macmillan Publishing.

Gelhar, L.W., C. Welty, and K.R. Rehfeldt (1992). A critical review of data on field scale dispersion in aquifers. Water Resources Research 28(7), 1955-1974.

Grisak, G.E. and J.F. Picken (1980a). Solute transport through fracture media 1 . The effect of matrix diffusion. Water Resources Research 16(4), 719-730.

Grisak, G.E. and J.F. Picken (1980b). Solute transport through fracture media 2. Column study of fractured till. Water Resources Research 16(4), 731-739. 
T. Bunsri et al. / JAFM , Vol. 1, No. 1, pp. 62-70, 2008.

James, R.V. and J. Rubin (1986). Transport of chloride ion in a water-unsaturated soil exhibiting anion exclusion. Soil Science Society of America Journal 50, 1142-1149.

Klute, A. (1986). Water retention: laboratory methods. In A. Klute et al. (Eds.), Method of soil analysis, Part 1 Physical and mineralogical methods, Agronomy, pp.635-662.

Mather, J.D., D.A. Gray and D.G. Jenkins (1969). The use of tracers to investigate the relationship between mining subsidence and groundwater occurrence of Aberdare, South Wales. Journal of Hydrology 9, 136-154.

Mattson, W. (1929). The law of soil colloidal behaviour I. Soil Science 27/28, 71-87.

Nützmann, G., S. Maciejewski and K.Joswig (2002). Estimation of water saturation dependence of dispersion in unsaturated porous media: experiment and modeling analysis. Advance Water Resources 25, 565-576.

Picken, J.F. and G.E. Grisak (1981). Scale-dependent dispersion in stratified aquifer. Water Resources Research 17(4), 1191-1211.

Rayment, G.E. and F.R. Higginson (1992). Australian laboratory handbook of soil and water chemical methods. Melbourne, AUS.: Inkata Press.

Sato, T., H. Tanahashi and H.A. Loáiciga (2003).Solute dispersion in variably saturated sand. Water Resources Research 39(6), 1155-1161.

Schnoor, J.L. (1996). Environmental Modelling: fate and transport of pollutants in water, air and soil. New York, USA.: A Wiley Interscience Publication.

Segerlind, L.J. (1984). Applied finite element analysis. New York, USA.: John Wiley \& Sons.

Ségol, G. (1993). Classical groundwater simulations: proving and improving numerical models. New York, USA.: PTR Prentice Hall.

Toride, N., M. Inoue and F.J. Leij (2003). Hydrodynamic dispersion in unsaturated dune sand. Soil Science Society of America Journal 63, 703-712.

van Genuchten, M.Th. (1980). A closed-form equation for predicting the hydraulic conductivity of unsaturated soils. Soil Science Society of America Journal 44, 892898. van Genuchten, M.Th. and P.J. Wierenga (1986). Solute dispersion coefficients and retardation factors. In A. Klute et al. (Eds.), Method of soil analysis, Part 1 Physical and mineralogical methods, Agronomy, pp.1025-1054.

Wallace, R. and T.S. Steenhuis (1998). Model for nonreactive solute transport in structure soils with continuous preferential flow path. Soil Science Society of America Journal 63, 703-712.

Warrick, A.W., J.W. Biggar and D.R. Nelson (1971).Simultaneous solute and water transfer for an unsaturated soil. Water Resources Research 7(5), 1216-1225. 
T. Bunsri et al. / JAFM , Vol. 1, No. 1, pp. 62-70, 2008.

Table 1- Details of soil column tests

\begin{tabular}{|c|c|c|c|c|c|}
\hline Tests & $\begin{array}{c}\text { Packing depth; } \\
\mathbf{~ c m}\end{array}$ & $\begin{array}{c}\text { NaCl } \\
\text { dosage; } \\
\mathbf{m g} / \mathbf{L}\end{array}$ & $\begin{array}{c}\text { Feeding rate; } \\
\mathbf{c m}^{\mathbf{3}} \mathbf{/ h}\end{array}$ & $\begin{array}{c}\text { Location of } \\
\text { tensiometers; } \mathbf{~ c m}\end{array}$ & $\begin{array}{c}\text { Location of EC(1:5) } \\
\text { measurements; } \mathbf{~ c m}\end{array}$ \\
\hline HP & 5 & 0 & 7.18 & 2.5 & None \\
T-1 & 5 & 200 & 7.18 & 2.5 & $0.5,1.5,2.5,3.5,4.5$ \\
T-2 & 5 & 500 & 7.18 & 2.5 & $0.5,1.5,2.5,3.5,4.5$ \\
T-3 & 20 & 500 & 7.18 & $2.5,6.5,14.0,17.5$ & $2.0,6.0,10,14,18$ \\
\hline
\end{tabular}

Note: HP is a hydraulic properties test. T-1, T-2 and T-3 are the tracer tests no.1, 2 and 3, respectively.

Table 2- Characteristics of topsoil sample

\begin{tabular}{|c|c|c|c|}
\hline Parameters & Values & Parameters & Values \\
\hline Particle size analysis & & Bulk density $\left(\mathrm{g} / \mathrm{cm}^{3}\right)$ & 1.28 \\
Sand content (\%) & 37.51 & Void ratio & 0.74 \\
Silt content (\%) & 43.79 & Moisture content $(\%)$ & 5.00 \\
Clay content (\%) & 18.70 & Soil EC $(1: 5)(\mathrm{mohs} / \mathrm{cm})$ & 0.129 \\
Texture & Loam & Sodium ion $(\mathrm{meq} / 100 \mathrm{~g}$ soil) & \\
$\mathrm{K}_{\mathrm{zz}}(\mathrm{cm} / \mathrm{h})$ & 0.662 & & 0.783 \\
Specific gravity & 2.55 & & \\
\hline
\end{tabular}

Table 3- Input parameters for Richards' equation

\begin{tabular}{|l|l|}
\hline Parameters & Values \\
\hline Domains & $5 \mathrm{~cm}$ (thin) and $20 \mathrm{~cm}$ (thick) \\
Boundary conditions & $\begin{array}{l}\text { Upper and lower } \psi \text { are }-0.005 \text { and } \\
-624 \mathrm{cmH}_{2} \mathrm{O}, \text { respectively. Initial } \psi \text { is }-624 \mathrm{cmH}_{2} \mathrm{O} . \\
14 \text { hours (thin) and } 72 \text { hours (thick) } \\
\text { Time domain }\end{array}$ \\
Number of time steps; $n t$ & 800 steps per hour (thin) and 1272 steps per hour (thick) \\
Nodal spacing; $d z$ & $0.125 \mathrm{~cm}$ (thin) and $0.25 \mathrm{~cm}$ (thick) \\
\hline
\end{tabular}

Table 4- Input parameters for tracer transport model

\begin{tabular}{|c|c|}
\hline Parameters & Values \\
\hline Domains & $5 \mathrm{~cm}(\mathrm{~T}-1$ and $\mathrm{T}-2)$ and $20 \mathrm{~cm}(\mathrm{~T}-3)$ \\
\hline $\mathrm{NaCl}$ conc. & $200 \mathrm{mg} / \mathrm{L}(\mathrm{T}-1)$ and $500 \mathrm{mg} / \mathrm{L}(\mathrm{T}-2$ and $\mathrm{T}-3)$ \\
\hline Nodal Darcy's velocity & Direct load from the Richards' equation \\
\hline $\mathrm{D}_{\mathrm{M}}$ & $0.04788 \mathrm{~cm}^{2} / \mathrm{h}$ \\
\hline Fraction for $D_{M}$ & 0.4 \\
\hline Boundary conditions & $\begin{array}{l}\text { Concentrations at the upper boundary are } 200(\mathrm{~T}-1) \text { or } 500(\mathrm{~T}-2 \text { and } \mathrm{T}-3) \mathrm{mg} / \mathrm{L} \text { and at the lower } \\
\text { boundary is } 0 \mathrm{mg} / \mathrm{L} \text {. The initial concentrations are } 200(\mathrm{~T}-1) \text { or } 500(\mathrm{~T}-2 \text { and } \mathrm{T}-3) \mathrm{mg} / \mathrm{L} \text {. }\end{array}$ \\
\hline Time domain & 14 hours (thin layer) and 72 hours (thick layer) \\
\hline Number of time steps; $n t$ & 800 steps per hour (thin) and 1272 steps per hour (thick) \\
\hline Nodal spacing; $d z$ & $0.125 \mathrm{~cm}$ (thin) and $0.25 \mathrm{~cm}$ (thick) \\
\hline
\end{tabular}


T. Bunsri et al. / JAFM , Vol. 1, No. 1, pp. 62-70, 2008.

Table 5- Average diffusion-dispersion coefficients for T-1

\begin{tabular}{|c|c|c|c|}
\hline Time (hour) & $\mathbf{D}_{\mathbf{z}}\left(\mathbf{c m}^{2} / \mathbf{h}\right)$ & Time (hour) & $\mathbf{D}_{\mathbf{z}}\left(\mathbf{c m}^{2} / \mathbf{h}\right)$ \\
\hline 3 & 0.0095 & 9 & 0.0356 \\
6 & 0.0133 & 11 & 0.1950 \\
\hline
\end{tabular}

Table 6- Average diffusion-dispersion coefficients for T-3

\begin{tabular}{|c|c|c|c|}
\hline Time (hour) & $\mathbf{D}_{\mathbf{z}}\left(\mathbf{c m}^{\mathbf{2}} / \mathbf{h}\right)$ & Time (hour) & $\mathbf{D}_{\mathbf{z}}\left(\mathbf{c m}^{\mathbf{2}} \mathbf{h}\right)$ \\
\hline 8 & 0.335 & 48 & 2.997 \\
16 & 0.746 & 56 & 3.028 \\
24 & 1.703 & 72 & 3.489 \\
\hline
\end{tabular}

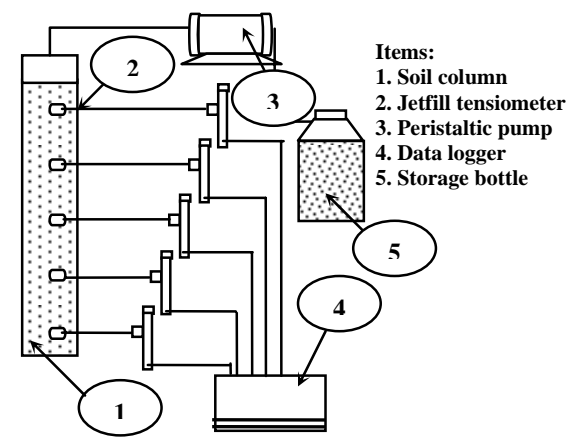

Fig. 1-Column set up.

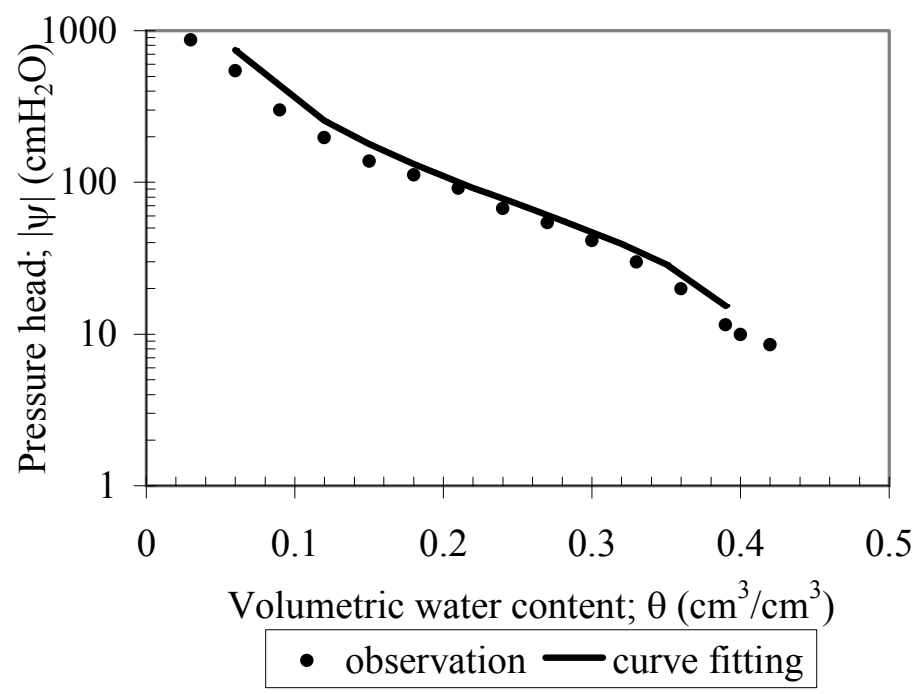

Fig. 2- Soil water retention curve fitting. 
T. Bunsri et al. / JAFM , Vol. 1, No. 1, pp. 62-70, 2008.

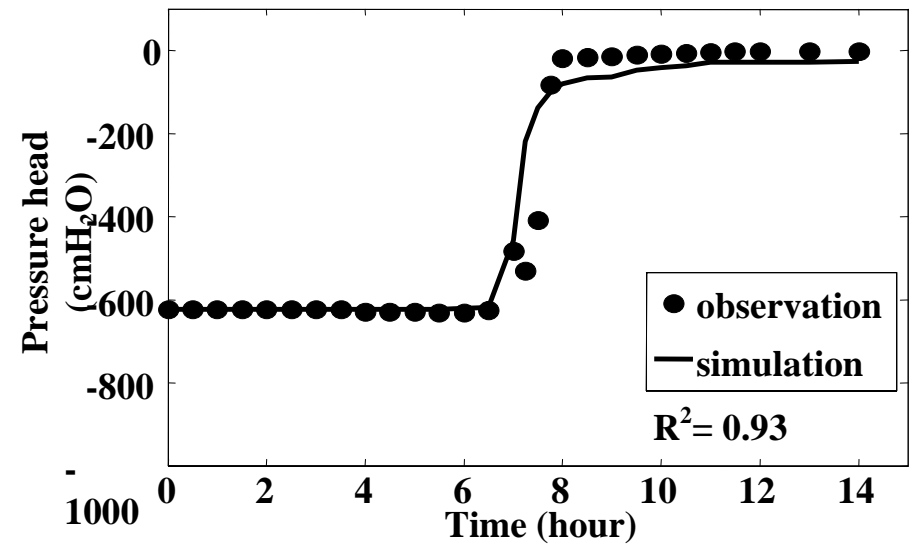

Fig. 3- Pressure head versus time for a thin layer unsaturated soil column.

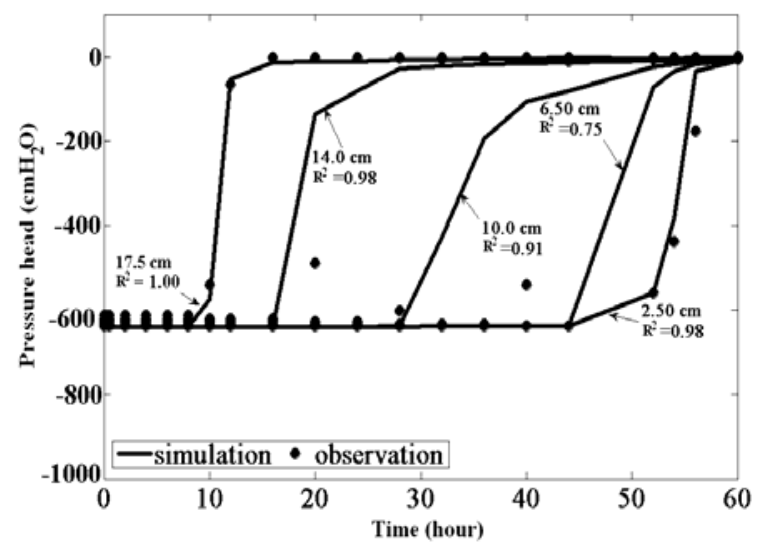

(Datum is at the column base and $\mathrm{R}^{2}$ is the residual square.)

Fig. 4- Elevated pressure head versus time for a thick soil layer unsaturated soil column.

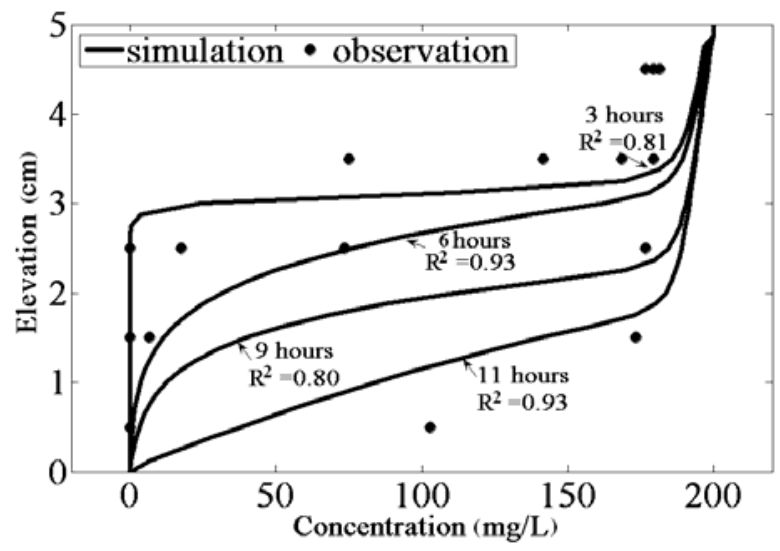

(Datum is at the column base and $\mathrm{R}^{2}$ is the residual square.)

Fig. 5- Concentration profiles for $\mathrm{T}-1$. 
T. Bunsri et al. / JAFM , Vol. 1, No. 1, pp. 62-70, 2008.

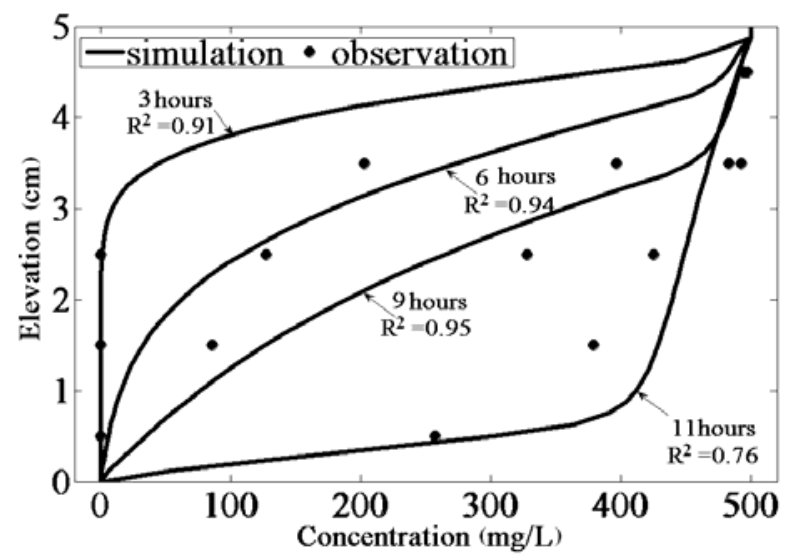

(Datum is at the column base and $\mathrm{R}^{2}$ is the residual square.)

Fig. 6- Concentration profiles for T-2.

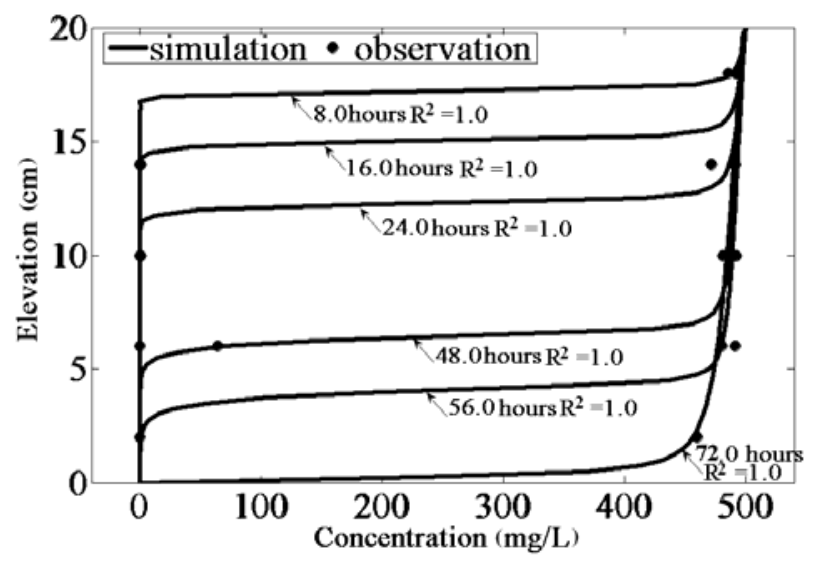

(Datum is at the column base and $\mathrm{R}^{2}$ is the residual square.)

Fig. 7- Concentration profiles for T-3. 